\title{
Correction to: Effects of a resistance and balance exercise programme on physical fitness, health-related quality of life and fear of falling in older women with osteoporosis and vertebral fracture: a randomized controlled trial
}

\author{
B. Stanghelle ${ }^{1} \cdot$ H. Bentzen ${ }^{1} \cdot$ L. Giangregorio ${ }^{2} \cdot$ A. H. Pripp ${ }^{3} \cdot$ D. A. Skelton ${ }^{4} \cdot$ A. Bergland $^{1}$ \\ Published online: 27 April 2020 \\ (C) International Osteoporosis Foundation and National Osteoporosis Foundation 2020
}

\section{Correction to: Osteoporosis International}

https://doi.org/10.1007/s00198-019-05256-4

The original version of this article, published on 10 January 2020, contained a mistake. An author's name was misspelled. The correct author name reads as follows:

\section{A. Skelton}

The original article has been corrected.

The online version of the original article can be found at https://doi.org/ 10.1007/s00198-019-05256-4

B. Stanghelle

bsugland@oslomet.no

H. Bentzen

hegben@ oslomet.no

L. Giangregorio

lora.giangregorio@uwaterloo.ca

A. H. Pripp

apripp@oslomet.no

D. A. Skelton

dawn.skelton@gcu.ac.uk

A. Bergland

astridb@oslomet.no
Institute of Physiotherapy, Faculty of Health Sciences, Oslo Metropolitan University, St. Olavs Plass, PO Box 4, 0130 Oslo, Norway

2 Department of Kinesiology, Schlegel-UW Research Institute for Aging, University of Waterloo, 250 Laurelwood Dr, Waterloo, ON N2J 0E2, Canada

3 Faculty of Health Sciences, Oslo Metropolitan University, St. Olavs Plass, PO Box 4, 0130 Oslo, Norway

4 School of Health and Life Sciences, Centre for Living, Glasgow Caledonian University, Cowcaddens Rd, Glasgow G4 0BA, UK 